Article

\title{
Enhanced Electrochromic Performance of All-Solid-State Electrochromic Device Based on W-Doped NiO Films
}

\author{
Xin Zhao ${ }^{1,2}$, Xiang Zhang ${ }^{1, *} \mathbb{0}$, Zhiwei Yin ${ }^{3}$, Wenjie $\mathrm{Li}^{3}$, Changpeng Yang ${ }^{2}$, Wenhai Sun ${ }^{1}$, Hulin Zhang ${ }^{1}$ \\ and $\mathrm{Yao}_{\mathrm{Li}}{ }^{1, *(\mathbb{D}}$ \\ 1 Center for Composite Materials and Structure, Harbin Institute of Technology, Harbin 150001, China; \\ zxbit@sina.com (X.Z.); 18810367851@163.com (W.S.); zhanghulinhit@163.com (H.Z.) \\ 2 Beijing Key Laboratory of Space Thermal Control Technology, Beijing Institute of Spacecraft System \\ Engineering, Beijing 100094, China; yangchangpeng501@163.com \\ 3 School of Chemistry and Chemical Engineering, Harbin Institute of Technology, Harbin 150001, China; \\ mryins@163.com (Z.Y.); liwenjie1917@163.com (W.L.) \\ * Correspondence: zhangxhit@hit.edu.cn (X.Z.); yaoli@hit.edu.cn (Y.L.)
}

check for updates

Citation: Zhao, X.; Zhang, X.; Yin, Z.; Li, W.; Yang, C.; Sun, W.; Zhang, H.;

Li, Y. Enhanced Electrochromic Performance of All-Solid-State

Electrochromic Device Based on W-Doped NiO Films. Coatings 2022, 12, 118. https://doi.org/10.3390/ coatings12020118

Academic Editor: Ivan Jerman

Received: 13 December 2021

Accepted: 13 January 2022

Published: 21 January 2022

Publisher's Note: MDPI stays neutral with regard to jurisdictional claims in published maps and institutional affiliations.

Copyright: (C) 2022 by the authors. Licensee MDPI, Basel, Switzerland. This article is an open access article distributed under the terms and conditions of the Creative Commons Attribution (CC BY) license (https:// creativecommons.org/licenses/by/ $4.0 /)$

\begin{abstract}
Electrochromic materials have attracted much attention due to their promising applications in smart windows and thermal control. However, $\mathrm{NiO}$ is a weak point for a complementary ECD and needs to be improved due to its low optical modulation and charge density. In this work, the W-doped $\mathrm{NiO}$ films are designed and prepared by RF magnetron co-sputtering to improve the performance of the $\mathrm{NiO}$. The results shows that the optical modulation of the $\mathrm{W}-\mathrm{NiO}(52.7 \%)$ is significantly improved compared with pure $\mathrm{NiO}(33.8 \%)$, which can be assigned to the increase in lattice boundaries due to the $\mathrm{W}$ doping. The response time of $\mathrm{W}-\mathrm{NiO}$ is $8.8 \mathrm{~s}$ for coloring and $7.2 \mathrm{~s}$ for bleaching, which is similar to that of $\mathrm{NiO}$ film. The all-solid-state electrochromic devices (ECDs) that employed $\mathrm{W}-\mathrm{NiO}$ as a complementary layer are prepared and exhibit a high-transmittance modulation of $48.5 \%$ in wavelengths of $450-850 \mathrm{~nm}$ and an emittance modulation of 0.28 in $2.5-25 \mu \mathrm{m}$, showing great application potential in the field of smart windows and spacecraft thermal control devices. The strategy of preparing $\mathrm{NiO}$ doped by $\mathrm{W}$ indicates an innovative direction to obtain ECDs with high performance.
\end{abstract}

Keywords: electrochromic; nickel oxide; tungsten doping; all-solid-state; emittance

\section{Introduction}

Electrochromism is a phenomenon that the optical properties of materials change reversibly by applying an external voltage, which involves the double injection/extraction of electrons and ions (i.e., $\mathrm{H}^{+}, \mathrm{Li}^{+}$) [1,2]. Recently, electrochromic materials have been a hot pot for their applications in smart windows $[3,4]$, camouflage $[5,6]$, rear-view mirror $[7,8]$, and thermal control devices [9]. The inorganic electrochromic (EC) materials are extensively studied due to their high thermal stability, easy preparation, as well as low cost [10]. NiO, one of the anodic EC materials, switching colors between colorless and gray, is usually used as a complementary layer to match with $\mathrm{WO}_{3}$ to assemble an electrochromic device (ECD) [11]. According to the type of electrolyte, the ECDs can be divided into liquid electrolyte ECDs, semi-solid electrolyte ECDs, and all-solid-state ECDs using solid-state electrolyte. Among them, all-solid-state ECDs have attracted most attention because of the excellent weather ability and stability [12].

Previous investigations show that $\mathrm{NiO}$ is a weak point for a complementary ECD due to its low optical modulation and charge density [13]. Therefore, various approaches have been used to improve the EC properties of $\mathrm{NiO}$ including organic-inorganic multi-layered hybrid films [14], doping [15,16] and microstructural building [17,18]. However, most approaches are realized by chemical methods, which are unsuitable for the preparation of the all-solid-state ECDs. NiO-based films can be prepared by electrodeposition [19], 
pulsed laser deposition [20], electron beam thermal evaporation [21], sol-gel process [22], chemical bath deposition [23], as well as sputtering [24,25]. Sputtering has attracted much interest due to its clean, harmless work condition, good quality of products, and continuous production; it is one of the main methods to prepare all-solid-state ECDs and can modify $\mathrm{NiO}$ by doping.

It is necessary to improve the optical modulation and charge density to better match with the EC layer when using $\mathrm{NiO}$ as a complementary layer in all-solid-state ECDs. Athenian et al. demonstrated that $\mathrm{Mg}, \mathrm{Al}, \mathrm{Si}, \mathrm{Zr}, \mathrm{Nb}$, and $\mathrm{Ta}$ doping can improve the EC performances compared to the undoped $\mathrm{NiO}$ films [26]. Zhao et al. reported that the EC performance including optical modulation and the response speed of $\mathrm{NiO}$ could be improved significantly by Sn doping [15].

Here, in order to improve the $\mathrm{EC}$ performance of $\mathrm{NiO}$ to better match the $\mathrm{WO}_{3}$ layer, $\mathrm{W}$-doped $\mathrm{NiO}$ films are prepared by magnetron sputtering, and the EC performances are investigated and compared with pure $\mathrm{NiO}$. The two films have similar surface morphology and crystalline structure. XPS results confirm that $\mathrm{W}$ was successfully doped into $\mathrm{NiO}$. The transmittance modulation increases to $52.7 \%$ after being doped by $\mathrm{W}$, which is larger than that of pure $\mathrm{NiO}$ film, indicating that $\mathrm{W}$ doping can significantly improve the performance of $\mathrm{NiO}$. The all-solid-state ECD with the structure of glass/ITO/W-NiO/LiTaO $3 / \mathrm{WO}_{3} / \mathrm{ITO}$ using $\mathrm{W}-\mathrm{NiO}$ as a complementary layer are prepared and investigated. The ECD shows an average transmittance modulation of $48.5 \%$ in the wavelength range of $450-850 \mathrm{~nm}$. In particular, the EC performances of the ECD in the infrared band are also studied, which is rarely reported in all-solid-state devices.

\section{Materials and Methods}

\subsection{Preparation of the $\mathrm{NiO}$ and $\mathrm{W}$-Doped $\mathrm{NiO}$ Films}

The $\mathrm{NiO}$ and $\mathrm{W}$-doped $\mathrm{NiO}$ (labeled as $\mathrm{W}-\mathrm{NiO}$ ) thin films were deposited onto ITOcoated glass $(1 \mathrm{~cm} \times 4 \mathrm{~cm}$, sheet resistance Rs $=6 \Omega$ /square) by radio frequency (RF) magnetron co-sputtering using $\mathrm{W}$ and a Ni metal target $(99.99 \%) 50 \mathrm{~mm}$ in diameter, which is schematically shown in Figure 1a. W and Ni targets were faced together, the power ratio was set to 0:80 and 10:70, and the total power was set to $80 \mathrm{~W} . \mathrm{O}_{2}$ content was set to $10 \%$ to ensure the transparency of the film, and the sputtering pressure was $1 \mathrm{~Pa}$. Before the deposition, the ITO glass substrate was ultrasonically cleaned with acetone, ethanol, and deionized water for $30 \mathrm{~min}$, respectively. The sputtering chamber was evacuated to $2 \times 10^{-3} \mathrm{~Pa}$, and the distance between the target and substrate was $6.5 \mathrm{~cm}$. The substrate with no additional heating was kept rotating to ensure the uniformity of the as-deposited films. The target was pre-sputtered for $10 \mathrm{~min}$ to remove the surface contamination to guarantee the film quality.
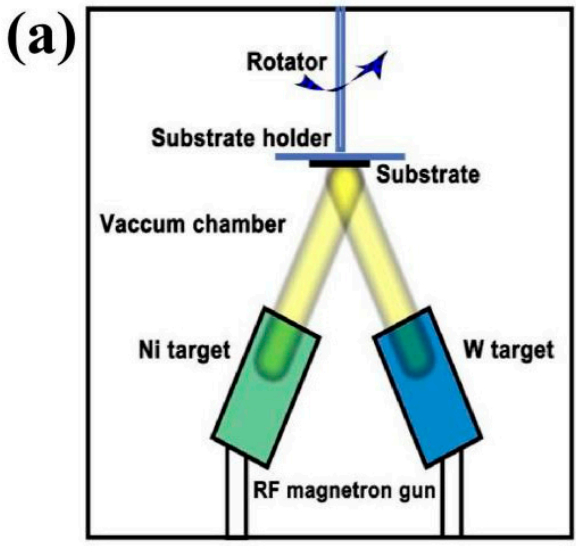
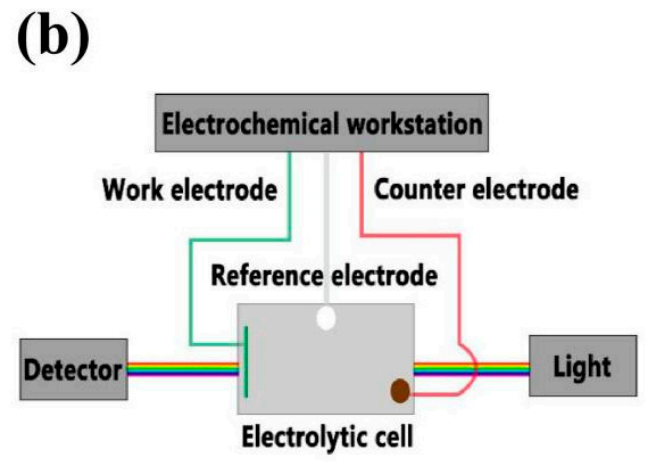

Figure 1. Schematic diagram of the equipment used for preparation and measurement. (a) RF magnetron co-sputtering equipment. (b) In situ spectral-electrochemical testing equipment. 


\subsection{Fabrication of the All-Solid-State ECDs}

The all-solid-state ECDs with the structure of glass/ITO/W-NiO/ $\mathrm{LiTaO} / \mathrm{WO}_{3} / \mathrm{ITO}$ were deposited by RF sputtering technology. The active area was $2 \times 2 \mathrm{~cm}^{2}$. All layers were deposited in the same chamber without breaking the vacuum. The as-deposited ECD was treated at $300{ }^{\circ} \mathrm{C}$ in air for $3 \mathrm{~h}$ to improve the conductivity of the top ITO electrode. The deposition parameters for each layer are listed in Table 1.

Table 1. Deposition parameters for the layers in the all-solid-state ECDs.

\begin{tabular}{ccccc}
\hline Layer & $\mathbf{O}_{\mathbf{2}} \mathbf{( \% )}$ & Pressure $\mathbf{( P a )}$ & Power $(\mathbf{W})$ & Time (min) \\
\hline $\mathrm{W}-\mathrm{NiO}$ & 10 & 1.0 & $10: 70$ & 120 \\
$\mathrm{LiTaO}_{3}$ & 5 & 1.0 & 100 & 480 \\
$\mathrm{NiO}$ & 50 & 1.0 & 100 & 150 \\
$\mathrm{ITO}$ & 1 & 0.4 & 50 & 60 \\
\hline
\end{tabular}

\subsection{Analytical Techniques}

The investigation on the surface and the cross-sectional morphologies of the asdeposited $\mathrm{NiO}, \mathrm{W}-\mathrm{NiO}$ films, and all-solid-state ECD was performed by scanning electron microscopy (SEM) using a Zeiss Supra55 microscope (Carl Zeiss AG, Jena, Germany). The crystalline structure of the $\mathrm{NiO}$ and $\mathrm{W}-\mathrm{NiO}$ films was studied by $\mathrm{X}$-ray diffraction (XRD, PANalytical B. V. Model X'pert Pro, Almelo, Netherland) with a Cu Ka radiation $(l=1.54 \AA)$ and a grazing angle of $0.5^{\circ}$. The composition of the $\mathrm{NiO}$ and $\mathrm{W}-\mathrm{NiO}$ films was investigated by X-ray photoelectron spectroscopy (XPS) using a PHI 5700 ESCA System, (Physical Electronics Inc., Chanhassen, MN, USA). IR measurements were performed using Fourier transform IR spectrophotometer (Bruker Vetex 70, Karlsruhe, Germany) with a gold-coated integrating sphere in reflectance mode.

An in situ spectra-electrochemical test was carried out using an electrochemical station (CHI 660E, Shanghai Chenhua Instruments, Shanghai, China) and Vis-NIR fiber optic spectrometer (MAYA 2000-Pro, Ocean Optics, Dunedin, FL, USA) to investigate the EC performance of the $\mathrm{NiO}, \mathrm{W}-\mathrm{NiO}$ films, and $\mathrm{ECD}$. The test equipment is schematically shown in Figure $1 \mathrm{~b}$. The $\mathrm{NiO}$ and $\mathrm{W}-\mathrm{NiO}$ films were measured in a three-electrode system where the films, Pt wire, and Ag wire were used as the working electrode, counter electrode, and reference electrode, respectively. The electrolyte was $0.5 \mathrm{M} \mathrm{LiClO}_{4}-\mathrm{PC}$ (propylene carbonate). Chronoamperometry (CA) measurements were performed at $\pm 1.5 \mathrm{~V}$ with a duration of $30 \mathrm{~s}$. The potential range of cyclic voltammetry $(\mathrm{CV})$ measurements was from -1.5 to $1.5 \mathrm{~V}$. The scan rate of $\mathrm{CV}$ measurements was $50 \mathrm{mV} / \mathrm{s}$. A two-electrode system was used for the test of ECD, where the top ITO layer near the $\mathrm{WO}_{3}$ layer was the working electrode and the bottom ITO layer was the reference and counter electrode. CA measurements were performed at $\pm 3 \mathrm{~V}$ with durations of 60 and $300 \mathrm{~s}$.

\section{Results and Discussion}

\section{1. $\mathrm{NiO}$ and $\mathrm{W}$-Doped $\mathrm{NiO}$ Films}

\subsubsection{Structure and Composition of $\mathrm{NiO}$ and $\mathrm{W}$-Doped $\mathrm{NiO}$ Films}

Figure 2a shows the surface and cross-sectional SEM images of the $\mathrm{NiO}$ and $\mathrm{W}-\mathrm{NiO}$ films. The surface morphology has a significant influence on the EC performance of the films because the EC reaction first occurs on the surface. The surface of the $\mathrm{NiO}$ and $\mathrm{W}-\mathrm{NiO}$ films is similar and relatively smooth; it is composed of small particles, which is beneficial to the stability. From the cross-sectional images (Figure $2 b, d$ ), it can be seen that the thicknesses of the $\mathrm{NiO}$ and $\mathrm{W}-\mathrm{NiO}$ films are about $135 \mathrm{~nm}$. 

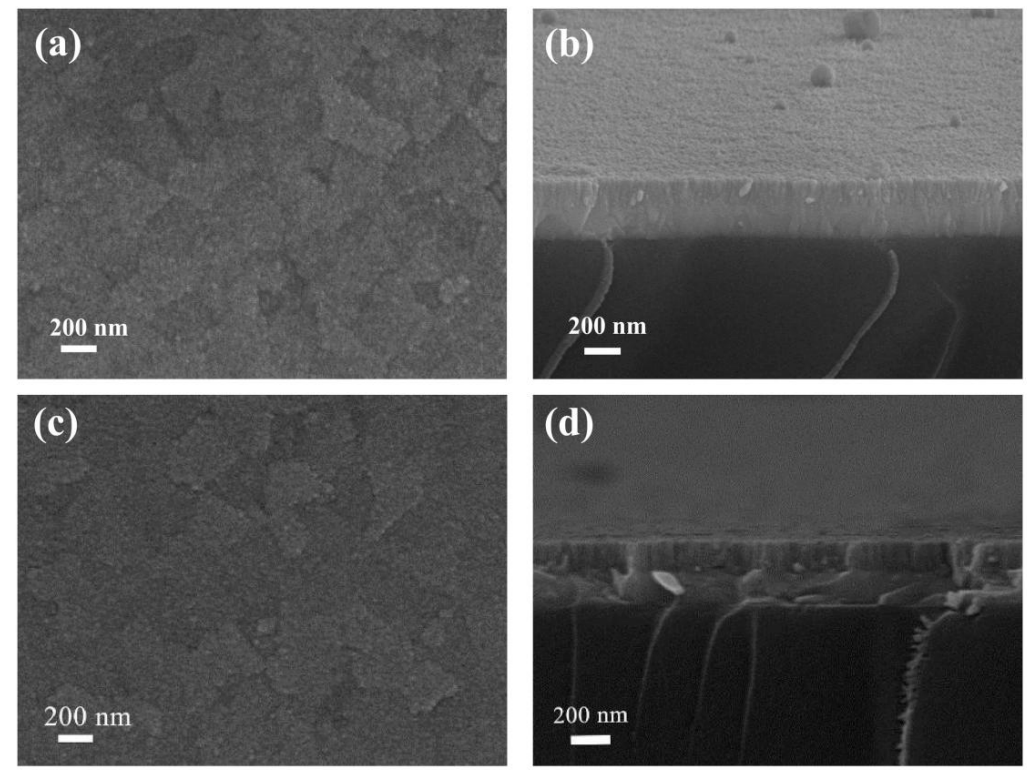

Figure 2. SEM images of the $\mathrm{NiO}$ and $\mathrm{W}-\mathrm{NiO}$ films. (a) Surface and (b) cross-sectional SEM images of the NiO film. (c) Surface and (d) cross-sectional SEM images of the W-NiO film.

The crystal structure of the $\mathrm{NiO}$ and $\mathrm{W}-\mathrm{NiO}$ films on the ITO-coated glass is investigated by XRD, as exhibited in Figure 3a. Both the prepared films show the diffraction peaks of the ITO substrate (JCPDS 65-3170) [27]. A characteristic peak at around $43^{\circ}$ can be observed in the patterns of $\mathrm{NiO}$ and $\mathrm{W}-\mathrm{NiO}$ films, which is corresponding to the (200) plane (JCPDS 73-1519) of cubic $\mathrm{NiO}$ [28]. In addition, compared with pure $\mathrm{NiO}$ film, the diffraction peak of the $\mathrm{W}-\mathrm{NiO}$ (200) plane shows a shift to high angle, indicating that the interplanar spacing becomes smaller after being doped by $\mathrm{W}$, because the ionic radius of $\mathrm{W}(0.62 \AA)$ is smaller than that of $\mathrm{Ni}(0.69 \AA)$ [29]. Moreover, no other characteristic peaks corresponding to $\mathrm{W}$ or the $\mathrm{W}$ compound are detected in the $\mathrm{W}-\mathrm{NiO}$ film, which implies that $\mathrm{W}$ is completely incorporated into the lattice of $\mathrm{NiO}$ or the $\mathrm{W}$ compound exists in amorphous form in the $\mathrm{W}-\mathrm{NiO}$ film.
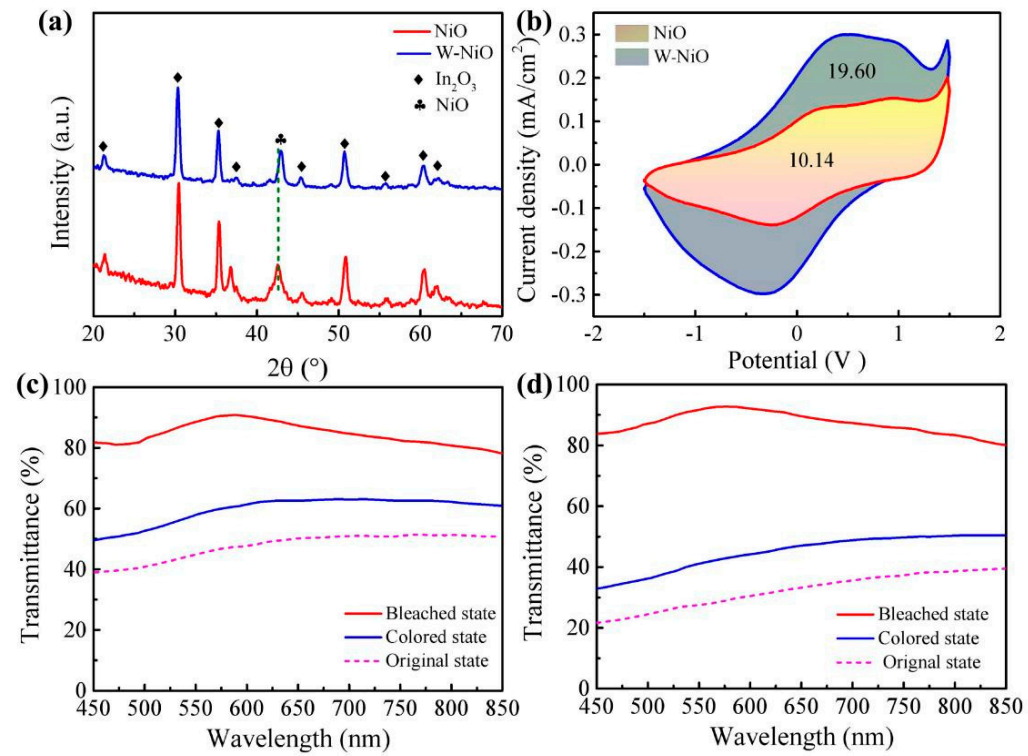

Figure 3. (a) XRD patterns. (b) $\mathrm{CV}$ curves of the $\mathrm{NiO}$ and $\mathrm{W}-\mathrm{NiO}$ films. (c) Transmittance spectra of $\mathrm{NiO}$ film. (d) Transmittance spectra of W-NiO film. 
XPS measurement is carried out to analyze the composition and chemical state of the element of the $\mathrm{NiO}$ and $\mathrm{W}-\mathrm{NiO}$ films, as shown in Figures $\mathrm{S} 1$ and S2. The spectra of the two samples show that the $\mathrm{NiO}$ film contains $\mathrm{Ni}, \mathrm{O}$, and $\mathrm{C}$, while $\mathrm{W}-\mathrm{NiO}$ additionally contains $\mathrm{W}$ with a peak at around $35.8 \mathrm{eV}$ corresponding to $\mathrm{W} 4 \mathrm{f}$. Ni $2 \mathrm{p}_{3 / 2}$ and $\mathrm{W} 4 \mathrm{f}$ XPS high-resolution spectra of the $\mathrm{W}-\mathrm{NiO}$ film are presented in Figure S2. The binding energy at $855.5 \mathrm{eV}$ is assigned to the $\mathrm{Ni} 2 \mathrm{p}_{3 / 2}$ peak with a satellite peak at $862.2 \mathrm{eV}$. The $\mathrm{Ni} 2 \mathrm{p}_{3 / 2}$ peak can be fitted to two peaks corresponding to two valence states of $\mathrm{Ni}$, which are $\mathrm{Ni}^{2+}$ in Ni-O bonds and $\mathrm{Ni}^{3+}$ mainly in $\mathrm{Ni}_{2} \mathrm{O}_{3}$, respectively, as shown in Figure S2a. It can be seen that $\mathrm{Ni}$ in the as-prepared $\mathrm{W}-\mathrm{NiO}$ is mainly $\mathrm{Ni}^{2+}$ [30]. The $\mathrm{W} 4 \mathrm{f}$ XPS high-resolution spectra can be fitted to $\mathrm{W}_{4} \mathrm{f}_{7 / 2}$ and $\mathrm{W}_{4} \mathrm{f}_{5 / 2}$ components, with the binding energies of 34.3 and $36.4 \mathrm{eV}$, respectively [31]. The results show that the $\mathrm{W}$ in the $\mathrm{W}-\mathrm{NiO}$ film is mainly $\mathrm{W}^{6+}$ with a proportion of $75.3 \%$.

\subsubsection{EC Performances of $\mathrm{NiO}$ and $\mathrm{W}$-Doped $\mathrm{NiO}$ Films}

Figure $3 \mathrm{~b}$ presents the $\mathrm{CV}$ curves of the $\mathrm{NiO}$ and $\mathrm{W}-\mathrm{NiO}$ films performed at a scan rate of $50 \mathrm{mV} / \mathrm{s}$. Both the films show obvious redox peaks corresponding to the conversion of $\mathrm{Ni}^{2+}$ and $\mathrm{Ni}^{3+}$ in the films, which is accompanied by the changes of colored and bleached states of the films. Compared with the $\mathrm{NiO}$ film, the $\mathrm{W}-\mathrm{NiO}$ film exhibits larger current density, and the charge density obtained by integrating the current density is $19.6 \mathrm{mC} / \mathrm{cm}^{2}$, which is almost twice as much as that of $\mathrm{NiO}$, indicating that $\mathrm{W}$ doping is conducive to improve the activity of the $\mathrm{EC}$ reaction of $\mathrm{NiO}$. Due to the large difference between the stable valence states of $\mathrm{Ni}(2+)$ and $\mathrm{W}(6+$ and $5+)$, the $\mathrm{W}$ ions of high oxidation state (6+ and $5+$ ) will cause a large disturbance in the lattice around the $\mathrm{W}$ cation inserted into the $\mathrm{Ni}$ site. Thus, the crystal structure of $\mathrm{NiO}$ becomes less dense compared with pure $\mathrm{NiO}$, which will lead to a large number of lattice boundaries, producing more lattice defects and active sites for the electrochromic reaction.

The EC performances of the films are measured, and the transmittance spectra of the $\mathrm{NiO}$ and $\mathrm{W}-\mathrm{NiO}$ films are displayed in Figure 3c,d. The as-prepared $\mathrm{W}-\mathrm{NiO}$ film shows a low transmittance in original state, which is about $20 \%$ lower than that of $\mathrm{NiO}$. When the negative voltage to the film is applied, the Li ions are injected into the film, and the film switches to the bleached state. The films switch to the colored state after the extraction of $\mathrm{Li}$ ions, and the transmittance of the colored state of the two films is higher than that of the original state, which may be related to the mechanism of $\mathrm{NiO}$ in $\mathrm{Li}$ salts electrolytes. The optical modulation of the $\mathrm{W}-\mathrm{NiO}$ film is obviously larger compared with $\mathrm{NiO}$ due to more ions participating in the reaction, which can be seen from the $\mathrm{CV}$ results.

The response time, defined as the time required to reach $90 \%$ of total transmittance modulation in the EC process [32], is one of the most important evaluation criterion of the EC materials. Figure $4 \mathrm{a}$ and $\mathrm{b}$ show the time-dependent transmittance spectra of the $\mathrm{NiO}$ and $\mathrm{W}-\mathrm{NiO}$ films. The optical modulation of the $\mathrm{NiO}$ film at $550 \mathrm{~nm}$ is $33.8 \%$ with the coloring time $\left(t_{c}\right)$ of $8.1 \mathrm{~s}$ and bleaching time $\left(t_{b}\right)$ of $4.1 \mathrm{~s}$. The $\mathrm{W}-\mathrm{NiO}$ film exhibits an obvious increase in optical modulation, which reaches $52.7 \%$, while the $t_{c}$ hardly changes. The $t_{b}$ increases due to the increase in the optical modulation [33].

Coloration efficiency $(\mathrm{CE})$, which means the change of optical density $(\triangle \mathrm{OD})$ per unit charge (Q), is an index to evaluate the energy-saving effect of the EC materials. It can be calculated according to the following equations [34]:

$$
\begin{gathered}
\Delta \mathrm{OD}=\log \left(\mathrm{t}_{\mathrm{b}} / \mathrm{t}_{\mathrm{c}}\right) \\
\mathrm{CE}=\Delta \mathrm{OD} / \Delta \mathrm{Q} .
\end{gathered}
$$

The $\mathrm{NiO}$ and $\mathrm{W}-\mathrm{NiO}$ films show similar $\mathrm{CE}$ values, which are 36.9 and $37.4 \mathrm{~cm}^{2} / \mathrm{C}$, respectively, as exhibited in Figure 4c,d. The above results indicate that the $\mathrm{W}$ doping can significantly improve the optical modulation of the $\mathrm{NiO}$ film without affecting other performances such as the response speed and CE. 

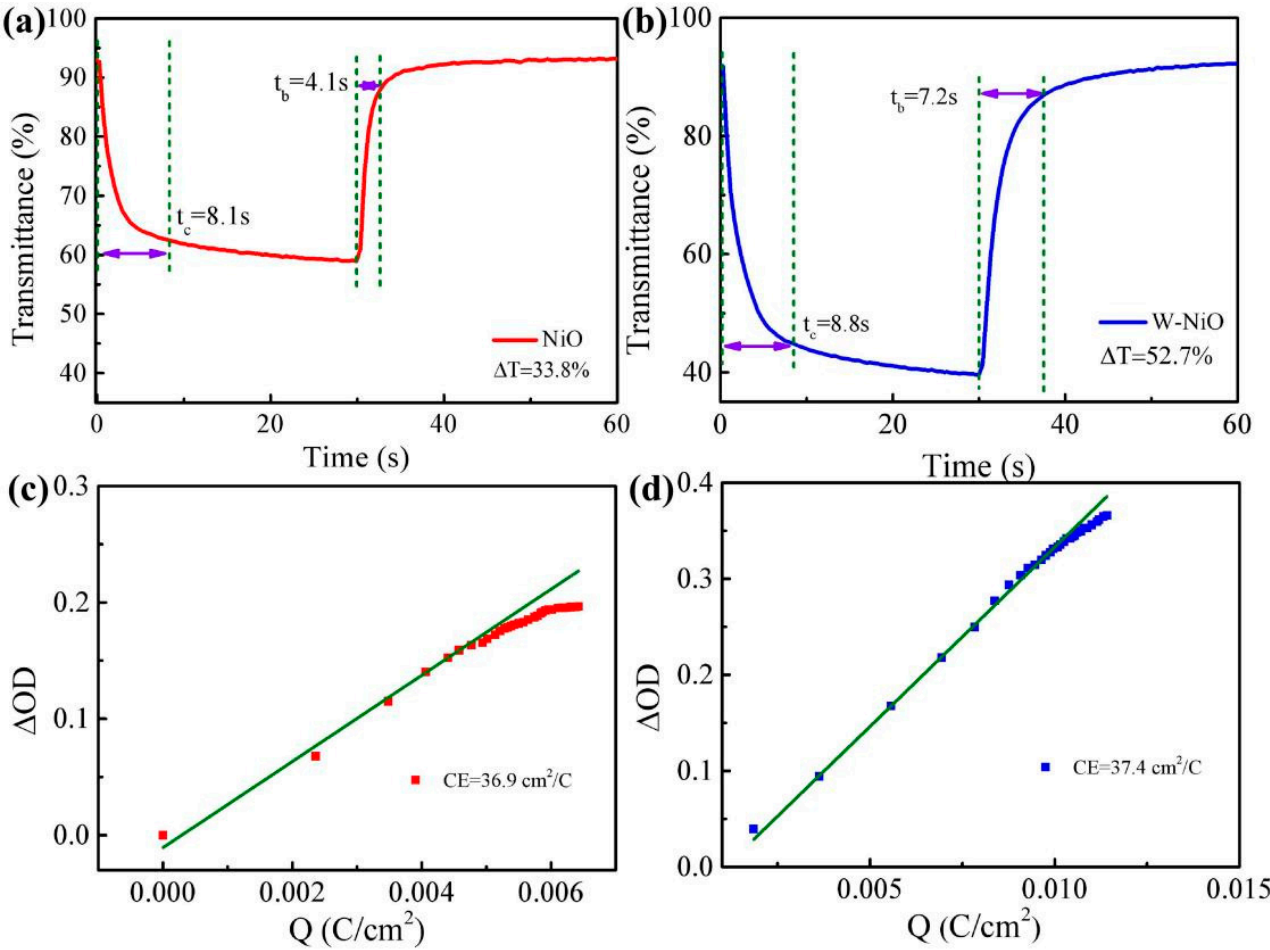

Figure 4. Time-dependent transmittance spectra (a) and CE (c) of the NiO film at $550 \mathrm{~nm}$. Timedependent transmittance spectra (b) and CE (d) of the W-NiO film at $550 \mathrm{~nm}$.

\subsection{All-Solid-State ECD Based on W-NiO Film}

\subsubsection{Morphology of the ECD}

The EC performances of $\mathrm{W}-\mathrm{NiO}$ film confirm that it has the potential to replace $\mathrm{NiO}$ as a complementary layer of $\mathrm{WO}_{3}$ in all-solid-state ECDs. Therefore, an ECD with structure of glass $/ \mathrm{ITO} / \mathrm{W}-\mathrm{NiO} / \mathrm{LiTaO}_{3} / \mathrm{WO}_{3} / \mathrm{ITO}$ is prepared, and the cross-section morphology of the ECD is characterized. Figure 5 shows the cross-section SEM image and the scheme of the ECD. The ECD exhibits a clearly identified five-layer structure, which are ITO, $\mathrm{W}-\mathrm{NiO}$, $\mathrm{LiTaO}_{3}, \mathrm{WO}_{3}$, and ITO from bottom to top with the thicknesses of 200, 135, 1190, 440, and $620 \mathrm{~nm}$, respectively. The closely connected interfaces indicate the physical and chemical stability of the ECD, which is important to the lifetime of the ECD.

(a)

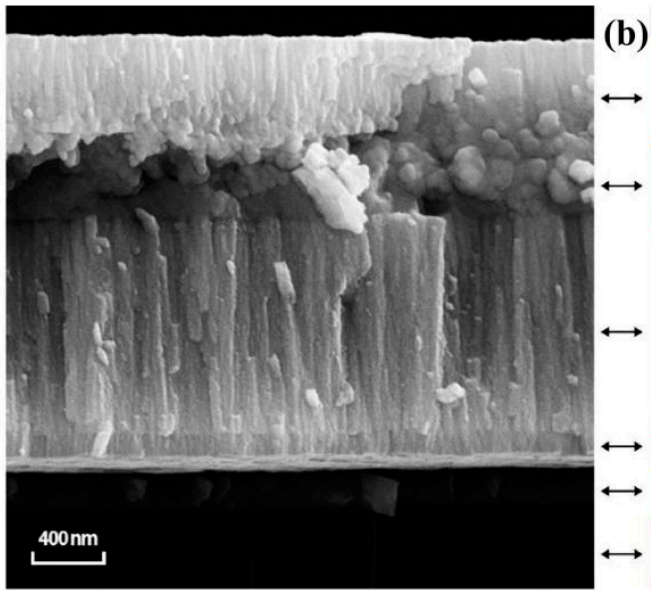

(b)

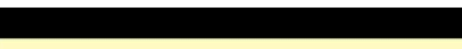

$\mathrm{WO}_{3}$

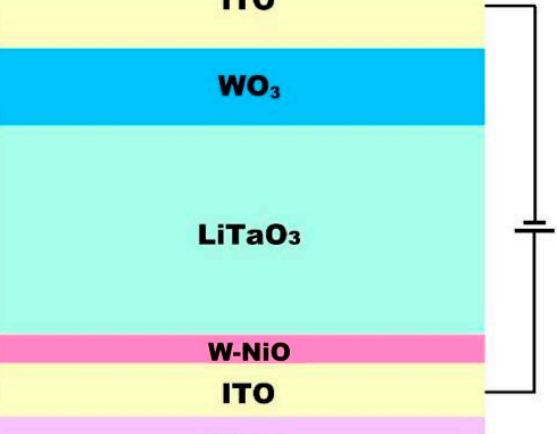

Glass

Figure 5. Cross-sectional SEM image (a) and schematic diagram (b) of the ECD. 


\subsubsection{EC Performances of the ECD}

The EC performances of the ECD are investigated. Figure 6a displays the transmittance spectra of the bleached and colored ECD after 150 cycles. The average transmittance spectra of the bleached state and colored state are $68.9 \%$ and $20.4 \%$, respectively, with an average optical modulation of $48.5 \%$. The time-dependent transmittance spectra in Figure $6 \mathrm{~b}$ indicates that the optical modulation of the ECD in $550 \mathrm{~nm}$ is $41.7 \%$ and the response speed is $37.5 \mathrm{~s}$ for coloring and $24.1 \mathrm{~s}$ for bleaching. The cyclic stability of the ECD is also studied and shown in Figure S3. The transmittance of the bleached state maintains stability in the first 70 cycles; then, it decreases slightly, and the transmittance of the colored state slowly goes down and finally tends to be stable. Figure S4 exhibits the transmittance spectra and digital photos of the ECD with a switching time of $300 \mathrm{~s}$. The transmittance of the ECD is lower than $10 \%$ after $300 \mathrm{~s}$ of coloring, and the average optical modulation is $60.8 \%$. The ECD with pure $\mathrm{NiO}$ is also prepared, and the performances are presented in Figures S5 and S6. The initial transmittance modulation at $550 \mathrm{~nm}$ is $43.8 \%$, which is much larger than that of ECD with $\mathrm{W}-\mathrm{NiO}$. However, it degrades rapidly due to the obvious decrease in the transmittance of the bleached state during cycling, indicating that $\mathrm{W}$ doping is beneficial to improve the stability of the ECD. The optical modulation of the ECD with pure $\mathrm{NiO}$ decreases to $30.8 \%$ after cycling with response times of $44.4 \mathrm{~s}$ for coloring and $26.3 \mathrm{~s}$ for bleaching, respectively, which is a little longer than that of the ECD with $\mathrm{W}-\mathrm{NiO}$. The EC performances of the modified $\mathrm{NiO}$ films and devices reported previously are listed in Table S1 for comparison.
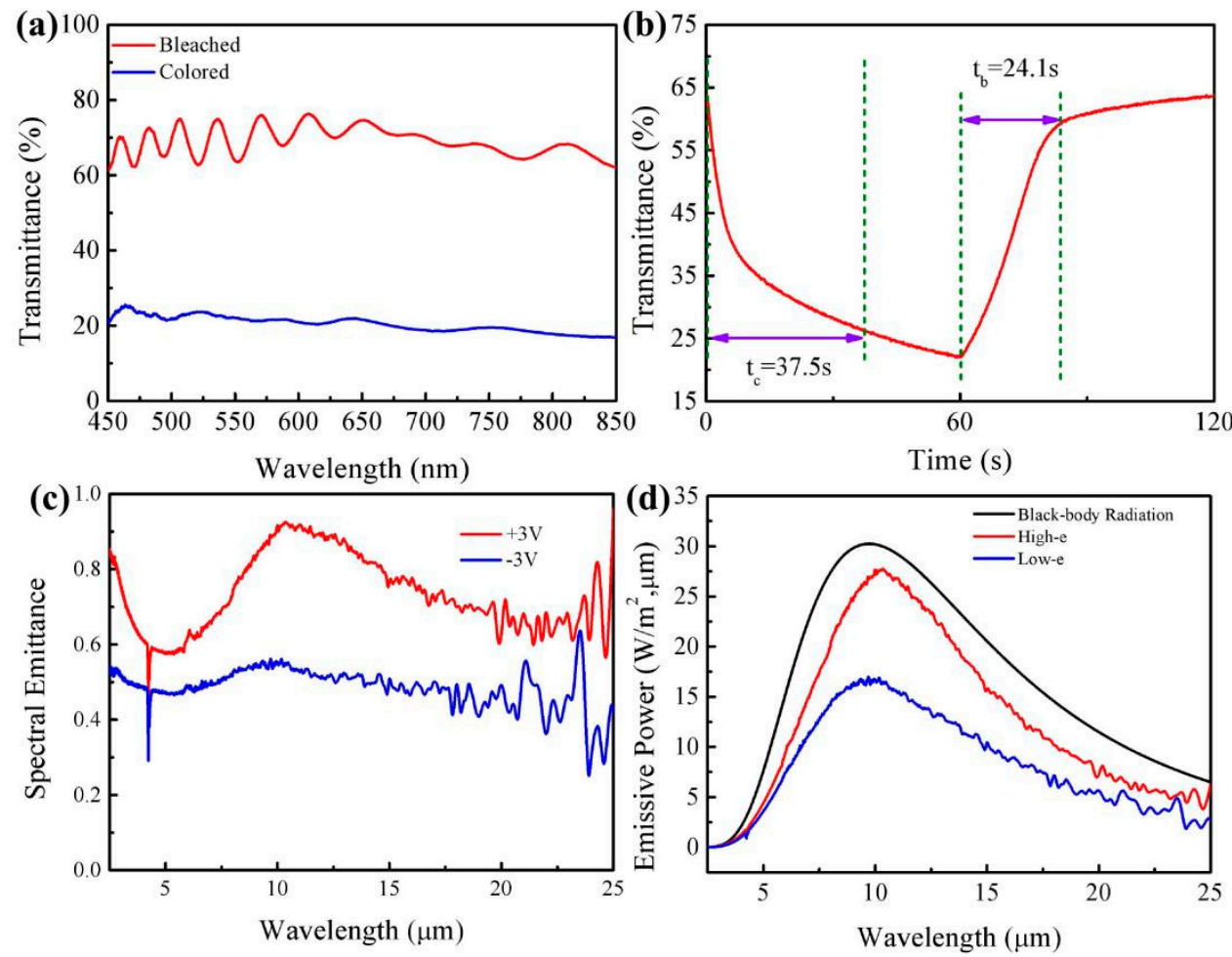

Figure 6. (a) Transmittance spectra, (b) Time-dependent transmittance spectra, (c) Spectral emittance curves, and (d) Emissive power curves of the ECD with W-NiO after 150 cycles.

Infrared emittance $(\varepsilon)$, including spectral emittance and emissive power, is one of the most important parameters for applications in the space thermal control field. However, there are few reports on the infrared emittance control of inorganic all-solid-state ECDs. According to Kirchhoff's law, the absorptivity is equal to the emittance for an object in thermal equilibrium [35]. The transmittance of the ITO glass substrate is almost zero in the wavelength range of 2.5-25 $\mu \mathrm{m}$ [35]. Thus, the spectral emittance can be obtained by the reflectance of the ECD. The spectral emittance of the prepared ECD is illustrated 
in Figure 6c. The absorptivity increases and the reflectance decreases when the ECD is colored at $-3 \mathrm{~V}$; thus, the ECD exhibits a high emittance of 0.77 . The absorptivity of the ECD decreases, and the ECD switches to the low emittance state (0.49) when the ECD is bleached at $+3 \mathrm{~V}$. The ECD exhibits an excellent emittance regulation ability with an emittance modulation value of 0.28 .

Emissive power is defined as the ratio of the radiant energy of an object at a certain temperature to the radiant energy of a standard blackbody and can be calculated according to the equations as follows [35]:

$$
\begin{gathered}
B_{\lambda}=\frac{c_{1} \lambda^{-5}}{\exp \left[\frac{c_{2}}{(\lambda T)}\right]-1} \\
\varepsilon=\frac{\int_{\lambda_{\min }}^{\lambda_{\max }}\left(1-\rho_{\lambda}\right) B_{\lambda} d \lambda}{\int_{\lambda_{\min }}^{\lambda_{\max }} B_{\lambda} d \lambda}
\end{gathered}
$$

$B_{\lambda}$ is radiation power at a certain wavelength, and $c_{1}$ and $c_{2}$ are the first and second radiation constant $\left(\mathrm{c}_{1}=3.7418 \times 10^{8} \mathrm{~W} \cdot \mu \mathrm{m}^{4} / \mathrm{m}^{2}, \mathrm{c}_{2}=1.4388 \times 10^{4} \mu \mathrm{m} \cdot \mathrm{K}\right)$.

Figure $6 \mathrm{~d}$ shows the emissive power spectra of the ECD in different emittance states and the ideal black-body spectrum at $298 \mathrm{~K}$. The emissive power of the ECD at -3 and $+3 \mathrm{~V}$ is 287 and $182 \mathrm{~W} / \mathrm{m}^{2}$ respectively, which indicates that the regulated emissive power of the ECD is $105 \mathrm{~W} / \mathrm{m}^{2}$ when applied in intelligent thermal control.

\section{Conclusions}

In this work, $\mathrm{NiO}$ and $\mathrm{W}$-doped $\mathrm{NiO}$ films are prepared by magnetron sputtering and the surface morphology, crystalline structure, chemical composition, electrochemical properties, and EC performances of the films are investigated. The results show that the charge density of $\mathrm{NiO}$ film increased remarkably after doping by $\mathrm{W}$ element; thus, the $\mathrm{W}-\mathrm{NiO}$ exhibits high optical modulation of $52.7 \%$, which is much larger than the value of $\mathrm{NiO}(33.8 \%)$. Meanwhile, the other $\mathrm{EC}$ indexes such as response time and $\mathrm{CE}$ are almost unaffected, indicating that $\mathrm{W}-\mathrm{NiO}$ film is promising to replace $\mathrm{NiO}$ as a component of all solid-state ECDs. The $\mathrm{W}-\mathrm{NiO}$ film is applied to an all-solid-state ECD with the structure of glass $/ \mathrm{ITO} / \mathrm{W}-\mathrm{NiO} / \mathrm{LiTaO}_{3} / \mathrm{WO}_{3} / \mathrm{ITO}$. The ECD shows a relatively high optical modulation of $41.7 \%$ at $550 \mathrm{~nm}$ with a response time of $37.5 \mathrm{~s}$ for coloring and $24.1 \mathrm{~s}$ for bleaching and excellent emittance regulation ability of 0.28 in wavelength of $2.5-25 \mu \mathrm{m}$. The above results demonstrate that the ECD using $\mathrm{W}-\mathrm{NiO}$ as a complementary layer can not only be applied in the smart window field but also show great potential in thermal control devices.

Supplementary Materials: The following are available online at https:/ /www.mdpi.com/article/10 .3390 / coatings12020118/s1, Figure S1: XPS spectra of the NiO and W-NiO films, Figure S2: (a) Highresolution spectra of Ni 2p. (b) High-resolution spectra of W4f, Figure S3: Cyclic stability of the ECD with $\mathrm{W}-\mathrm{NiO}$ measured at $\pm 3 \mathrm{~V}$ with a duration of $60 \mathrm{~s}$, Figure S4: Transmittance spectra and digital photos of the ECD with $\mathrm{W}-\mathrm{NiO}$ measured at $\pm 3 \mathrm{~V}$ with a duration of 300 s, Figure S5: (a) Time dependent transmittance spectra, (b) Transmittance spectra of the ECD with NiO after 150 cycles, Figure S6: Cyclic stability of the ECD with $\mathrm{NiO}$ measured at $\pm 3 \mathrm{~V}$ with a duration of $60 \mathrm{~s}$, Table S1: Comparison of the $\mathrm{W}-\mathrm{NiO}$ film and ECD with previously reported data.

Author Contributions: X.Z. (Xin Zhao) and Z.Y. carried out the tests and wrote the manuscript, X.Z. (Xin Zhao), X.Z. (Xiang Zhang), W.L., C.Y., W.S. and H.Z. performed the analysis of the results and assisted in the test, X.Z. (Xiang Zhang), Y.L. and Z.Y. contributed to the concept and modified the manuscript. All authors have read and agreed to the published version of the manuscript.

Funding: This research received no external funding.

Institutional Review Board Statement: Not applicable.

Informed Consent Statement: Not applicable. 
Data Availability Statement: The data presented in this study are available on request from the corresponding author.

Conflicts of Interest: The authors declare no conflict of interest.

\section{References}

1. Granqvist, C.G. Electrochromics for smart windows: Oxide-based thin films and devices. Thin Solid Films 2014, 564, 1-38. [CrossRef]

2. Dong, D.; Djaoued, H.; Vienneau, G.; Robichaud, J.; Brown, D.; Brüning, R.; Djaoued, Y. Electrochromic and colorimetric properties of anodic NiO thin films: Uncovering electrochromic mechanism of NiO. Electrochim. Acta 2020, 335, 135648. [CrossRef]

3. Pan, J.; Zheng, R.; Wang, Y.; Ye, X.; Wan, Z.; Jia, C.; Weng, X.; Xie, J.; Deng, L. A high-performance electrochromic device assembled with hexagonal $\mathrm{WO}_{3}$ and $\mathrm{NiO} / \mathrm{PB}$ composite nanosheet electrodes towards energy storage smart window. Sol. Energy Mater. Sol. Cells 2020, 207, 110337. [CrossRef]

4. Zhao, Q.; Wang, J.; Cui, Y.; Ai, X.; Chen, Z.; Cao, C.; Xu, F.; Gao, Y. The discovery of conductive ionic bonds in NiO/Ni transparent counter electrodes for electrochromic smart windows with an ultra-long cycling life. Mater. Adv. 2021, 2, 4667-4676. [CrossRef]

5. Xu, Z.; Li, W.; Huang, J.; Guo, X.; Liu, Q.; Yu, R.; Miao, W.; Zhou, B.; Guo, W.; Liu, X. Flexible, controllable and angle-independent photoelectrochromic display enabled by smart sunlight management. Nano Energy 2019, 63, 103830. [CrossRef]

6. Zhang, X.; Li, W.; Li, X.; Wang, L.; Sun, W.; Zhang, H.; Wang, J.; Zhao, J.; Li, Y. Bio-inspired electrochromic skin based on tungsten oxide. Sol. Energy Mater. Sol. Cells 2021, 230, 111195. [CrossRef]

7. Shah, K.W.; Wang, S.X.; Soo, D.X.Y.; Xu, J. Viologen-based electrochromic materials: From small molecules, polymers and composites to their applications. Polymers 2019, 11, 1839. [CrossRef] [PubMed]

8. Xu, Z.; Qiu, W.; Fan, X.; Shi, Y.; Gong, H.; Huang, J.; Patil, A.; Li, X.; Wang, S.; Lin, H.; et al. Stretchable, stable, and degradable silk fibroin enabled by mesoscopic doping for finger motion triggered color/transmittance adjustment. ACS Nano 2021, 15, 12429-12437. [CrossRef] [PubMed]

9. Mandal, J.; Du, S.; Dontigny, M.; Zaghib, K.; Yu, N.; Yang, Y. $\mathrm{Li}_{4} \mathrm{Ti}_{5} \mathrm{O}_{12}$ : A visible-to-infrared broadband electrochromic material for optical and thermal management. Adv. Funct. Mater. 2018, 28, 1-8. [CrossRef]

10. Zhang, X.; Li, W.; Chen, X.; Zhao, Y.; Wang, L.; Chen, M.; Li, Z.; Li, Y. Inorganic all-solid-state electrochromic devices with reversible color change between yellow-green and emerald green. Chem. Commun. 2020, 56, 10062-10065. [CrossRef]

11. Huang, H.; Tian, J.; Zhang, W.K.; Gan, Y.P.; Tao, X.Y.; Xia, X.H.; Tu, J.P. Electrochromic properties of porous NiO thin film as a counter electrode for $\mathrm{NiO} / \mathrm{WO}_{3}$ complementary electrochromic window. Electrochim. Acta 2011, 56, 4281-4286. [CrossRef]

12. Li, W.; Zhang, X.; Chen, X.; Zhao, Y.; Sun, W.; Xiao, Y.; Li, S.; Zhao, J.; Li, Y. Long life all-solid-state electrochromic devices by annealing. Sol. Energy Mater. Sol. Cells 2021, 224, 110992. [CrossRef]

13. Green, S.; Backholm, J.; Georén, P.; Granqvist, C.G.; Niklasson, G.A. Electrochromism in nickel oxide and tungsten oxide thin films: Ion intercalation from different electrolytes. Sol. Energy Mater. Sol. Cells 2009, 93, 2050-2055. [CrossRef]

14. Sonavane, A.C.; Inamdar, A.I.; Dalavi, D.S.; Deshmukh, H.P.; Patil, P.S. Simple and rapid synthesis of NiO/PPy thin films with improved electrochromic performance. Electrochim. Acta 2010, 55, 2344-2351. [CrossRef]

15. Zhao, Y.; Zhang, X.; Chen, X.; Li, W.; Wang, L.; Li, Z.; Zhao, J.; Endres, F.; Li, Y. Preparation of Sn-NiO films and all-solid-state devices with enhanced electrochromic properties by magnetron sputtering method. Electrochim. Acta 2021, 367, 137457. [CrossRef]

16. Firat, Y.E.; Peksoz, A. Efficiency enhancement of electrochromic performance in NiO thin film via Cu doping for energy-saving potential. Electrochim. Acta 2019, 295, 645-654. [CrossRef]

17. Choi, D.; Son, M.; Im, T.; Ahn, S.H.; Lee, C.S. Microstructure control of NiO-based ion storage layer with various sized NiO particles to evaluate the electrochromic performance. Mater. Chem. Phys. 2020, 249, 123121. [CrossRef]

18. Yu, J.H.; Nam, S.H.; Gil, Y.E.; Boo, J.H. The effect of ammonia concentration on the microstructure and electrochemical properties of $\mathrm{NiO}$ nanoflakes array prepared by chemical bath deposition. Appl. Surf. Sci. 2020, 532, 147441. [CrossRef]

19. Yuan, Y.F.; Xia, X.H.; Wu, J.B.; Chen, Y.B.; Yang, J.L.; Guo, S.Y. Enhanced electrochromic properties of ordered porous nickel oxide thin film prepared by self-assembled colloidal crystal template-assisted electrodeposition. Electrochim. Acta 2011, 56, 1208-1212. [CrossRef]

20. Penin, N.; Rougier, A.; Laffont, L.; Poizot, P.; Tarascon, J.M. Improved cyclability by tungsten addition in electrochromic NiO thin films. Sol. Energy Mater. Sol. Cells 2006, 90, 422-433. [CrossRef]

21. Pereira, S.; Gonçalves, A.; Correia, N.; Pinto, J.; Pereira, L.; Martins, R.; Fortunato, E. Electrochromic behavior of NiO thin films deposited by e-beam evaporation at room temperature. Sol. Energy Mater. Sol. Cells 2014, 120, 109-115. [CrossRef]

22. Ren, Y.; Zhou, X.; Zhang, H.; Lei, L.; Zhao, G. Preparation of a porous NiO array-patterned film and its enhanced electrochromic performance. J. Mater. Chem. C 2018, 6, 4952-4958. [CrossRef]

23. Yang, H.; Yu, J.H.; Seo, H.J.; Jeong, R.H.; Boo, J.H. Improved electrochromic properties of nanoporous NiO film by NiO flake with thickness controlled by aluminum. Appl. Surf. Sci. 2018, 461, 88-92. [CrossRef]

24. Chang, J.Y.; Chen, Y.C.; Wang, C.M.; Chen, Y.W. Electrochromic properties of Li-Doped NiO films prepared by RF magnetron sputtering. Coatings 2020, 10, 87. [CrossRef] 
25. Azevedo, C.F.; Balboni, R.D.C.; Cholant, C.M.; Moura, E.A.; Lemos, R.M.J.; Pawlicka, A.; Gündel, A.; Flores, W.H.; Pereira, M.; Avellaneda, C.O. New thin films of $\mathrm{NiO}$ doped with $\mathrm{V}_{2} \mathrm{O}_{5}$ for electrochromic applications. J. Phys. Chem. Solids 2017, 110, 30-35. [CrossRef]

26. Avendaño, E.; Azens, A.; Niklasson, G.A.; Granqvist, C.G. Electrochromism in nickel oxide films containing Mg, Al, Si, V., Zr, Nb, Ag, or Ta. Sol. Energy Mater. Sol. Cells 2004, 84, 337-350. [CrossRef]

27. Yu, L.; Huang, Y.; Xiao, G.; Li, D. Application of long wavelength visible light $(\lambda>650 \mathrm{~nm})$ in photocatalysis with a p-CuO-n- $\mathrm{In}_{2} \mathrm{O}_{3}$ quantum dot heterojunction photocatalyst. J. Mater. Chem. A 2013, 1, 9637-9640. [CrossRef]

28. Zhou, K.; Qi, Z.; Zhao, B.; Lu, S.; Wang, H.; Liu, J.; Yan, H. The influence of crystallinity on the electrochromic properties and durability of $\mathrm{NiO}$ thin films. Surf. Interfaces 2017, 6, 91-97. [CrossRef]

29. Hartman, P.; Chan, H.K. Application of the periodic bond chain (PBC) theory and attachment energy consideration to derive the crystal morphology of hexamethylmelamine. Pharm. Res. 1993, 10, 1052-1058. [CrossRef] [PubMed]

30. Biesinger, M.C.; Payne, B.P.; Lau, L.W.M.; Gerson, A.; Smart, R.S.C. X-ray photoelectron spectroscopic chemical state Quantification of mixed nickel metal, oxide and hydroxide systems. Surf. Interface Anal. 2009, 41, 324-332. [CrossRef]

31. Zhang, J.; Tu, J.P.; Xia, X.H.; Qiao, Y.; Lu, Y. An all-solid-state electrochromic device based on $\mathrm{NiO} / \mathrm{WO}_{3}$ complementary structure and solid hybrid polyelectrolyte. Sol. Energy Mater. Sol. Cells 2009, 93, 1840-1845. [CrossRef]

32. Chen, P.W.; Chang, C.T.; Ko, T.F.; Hsu, S.C.; Li, K.D.; Wu, J.Y. Fast response of complementary electrochromic device based on $\mathrm{WO}_{3} / \mathrm{NiO}$ electrodes. Sci. Rep. 2020, 10, 1-12. [CrossRef] [PubMed]

33. Li, W.; Zhang, X.; Chen, X.; Zhao, Y.; Wang, L.; Chen, M.; Li, Z.; Zhao, J.; Li, Y. Lithiation of $\mathrm{WO}_{3}$ films by evaporation method for all-solid-state electrochromic devices. Electrochim. Acta 2020, 355, 136817. [CrossRef]

34. Li, W.; Zhang, X.; Chen, X.; Zhao, Y.; Wang, L.; Chen, M.; Zhao, J.; Li, Y.; Zhang, Y. Effect of independently controllable electrolyte ion content on the performance of all-solid-state electrochromic devices. Chem. Eng. J. 2020, 398, 125628. [CrossRef]

35. Zhang, X.; Tian, Y.; Li, W.; Dou, S.; Wang, L.; Qu, H.; Zhao, J.; Li, Y. Preparation and performances of all-solid-state variable infrared emittance devices based on amorphous and crystalline $\mathrm{WO}_{3}$ electrochromic thin films. Sol. Energy Mater. Sol. Cells 2019, 200, 109916. [CrossRef] 